\title{
Portable measurement of maximum mouth pressures
}

\author{
C-H. Hamnegård*, S. Wragg\#, D. Kyroussis\#, R. Aquilina\#, \\ J. Moxham+, M. Green\#
}

Portable measurement of maximum mouth pressures. C-H. Hamnegård, S. Wragg, D. Kyroussis, R. Aquilina, J. Moxham, M. Green. CERS Journals Ltd 1994.

ABSTRACT: We have compared a small portable mouth pressure meter (MPM) to our laboratory standard (LS) pressure recording equipment in order to evaluate this new device.

The mouth pressure meter measures and displays as a digital read-out peak pressure for inspiratory and expiratory efforts. It samples the signal at $16 \mathrm{~Hz}$, and an integral microprocessor is programmed to determine and display the maximum pressure averaged over one second both during inspiratory and expiratory manoeuvres (PImax and Pemax, respectively). A fine bore catheter connecting the mouthpiece of the mouth pressure meter to a Validyne pressure transducer enabled simultaneous measurement of pressure, which was analysed by LabVIEW, running on a Macintosh Quadra 700 computer. We studied 13 normal subjects and 11 patients with respiratory disease. Each subject performed inspiratory and five expiratory efforts. The values displayed from the mouth pressure meter were manually recorded.

The mouth pressure meter reliably and accurately measured peak pressure and maximal pressure both for inspiratory and expiratory efforts in normals and patients. The mean \pm SD difference when compared with the Validyne method was $0.19 \pm 0.12$ and $-0.04 \pm 0.12 \mathrm{kPa}$, for PImax and Pemax, respectively.

This portable device should be useful to measure mouth pressures, not only in the routine lung function laboratory but also at the bedside and in the clinic. Eur Respir J., 1994, 7, 398-401.
"Respiratory Muscle Laboratory, National Heart and Lung Institute, Brompton Hospital, London, UK. 'Dept of Thoracic Medicine, King's College Hospital, London, UK. *Dept of Pulmonary Medicine, Renströmska Hospital, Gothenburg, Sweden.

Correspondence: M. Green Respiratory Muscle Laboratory National Heart and Lung Institute Brompton Hospital Fulham Road

London SW3 6HP UK

Keywords: Mouth pressure respiratory muscles respiratory strength

Received: May 111993

Accepted after revision August 221993
Respiratory muscle weakness is a common feature of neuromuscular disease. It is often useful to measure respiratory muscle strength, both to determine whether there is weakness and to quantify its severity [1]. In some patients presenting with respiratory symptoms, the possibility of respiratory muscle weakness may not previously have been considered, and measurement of respiratory muscle strength is of help in diagnosis and management. In patients found to have respiratory muscle weakness, repeated measurements enable the progress of the disease and response to treatment to be monitored.

The simplest scientific measurements of respiratory muscle strength are maximum inspiratory (PImax) and expiratory (PEmax) mouth pressures [2-5]. Normal values have been widely established in a variety of populations [2, 3, 6-9]. Routine measurement of mouth pressures has not usually been feasible in the chest clinic or at the bedside, because of the need for laboratory based equipment which is complex, expensive and not portable. A hand-held device has been developed that enables convenient measurement of mouth pressures in most clinical settings (fig. 1). Requirements for such

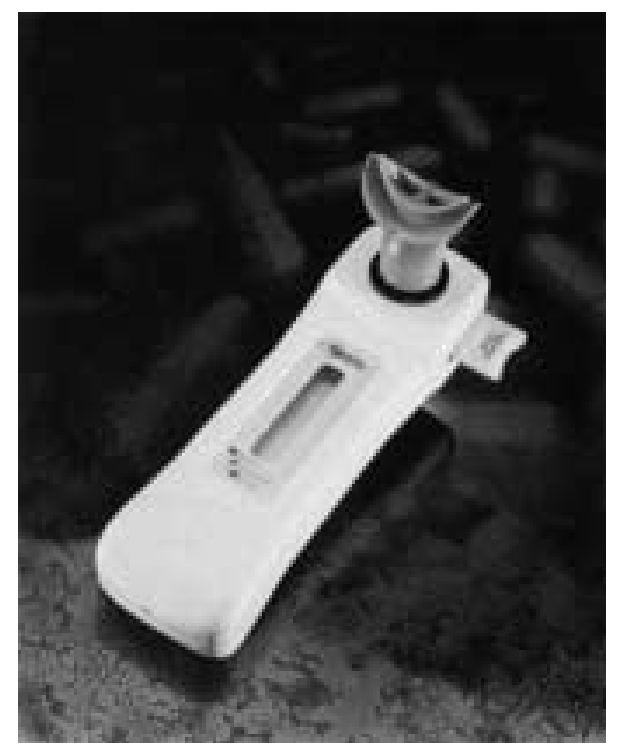

Fig. 1. - Photograph of mouth pressure meter (MPM).

a device are reliability, accuracy and ease of operation. We have therefore compared the mouth pressure meter (MPM) to our laboratory standard (LS) equipment. 

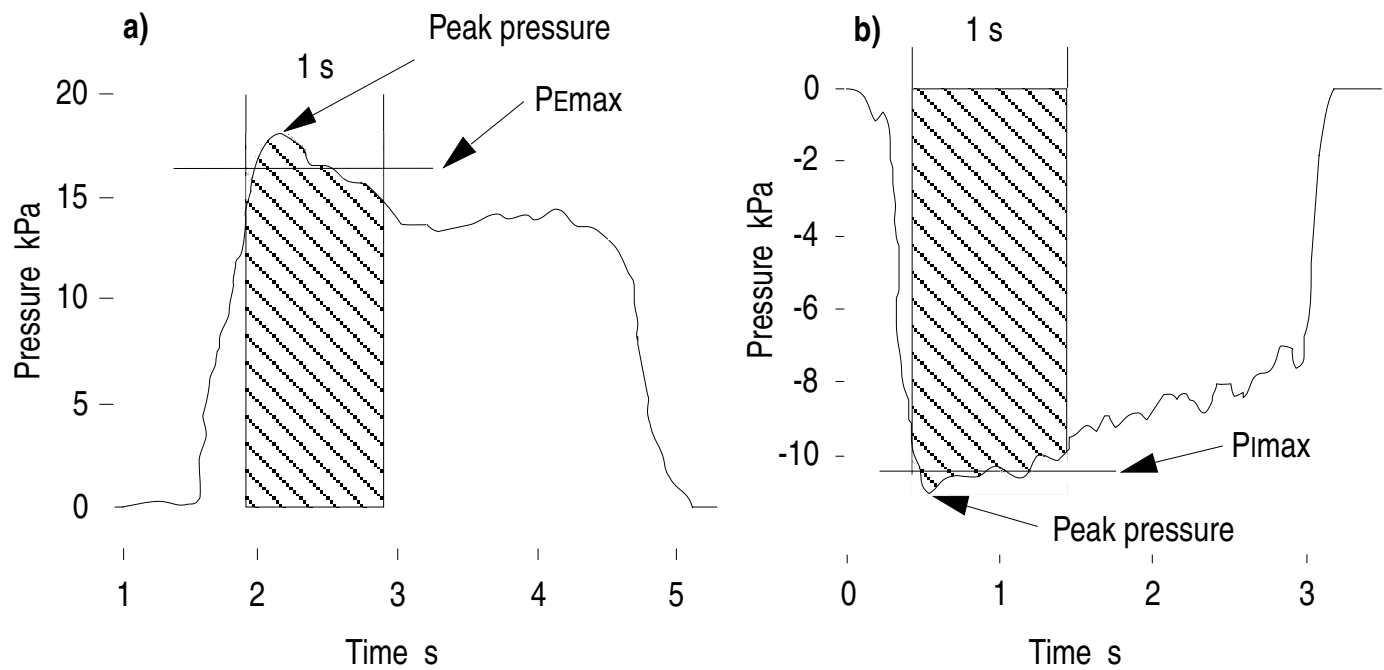

Fig. 2. - a) A typical pressure trace from a subject performing a maximal expiratory pressure (Pemax) manoeuvre. The mouth pressure meter is programmed to determine the peak pressure and the one second period (shaded area) which is averaged to give the Pemax. b) A pressure trace from a subject performing a maximal inspiratory pressure (PImax) manoeuvre to show peak pressure and PImax.

\section{Materials and methods}

The mouth pressure meter (Precision Medical, UK) has a disposable mouthpiece [8], a valve and small leak. Internally, there is a ceramic solid state pressure transducer, a microprocessor and a digital pressure display. The microprocessor, sampling at $16 \mathrm{~Hz}$, is programmed to determine the maximum pressure averaged over one second (Pmax) and the peak pressure both for inspiratory and expiratory efforts (fig. $2 a$ and b). To activate measurement, the subject must achieve a pressure of 2 $\mathrm{kPa}$. If pressure is maintained for less than $0.5 \mathrm{~s}$ the display indicates "sample rejected, too short". If pressure is sustained for $0.5-1.5 \mathrm{~s}$ the meter displays "short sample" and the peak pressure. If pressure is sustained for more than $1.5 \mathrm{~s}$ both peak pressure and Pmax are displayed.

Our "laboratory standard" recording equipment consists of a Validyne MP45-1 differential pressure transducer, range $\pm 20 \mathrm{kPa}$ (Validyne Co., Northridge, CA, USA), a carrier amplifier (Validyne Co.), a 12-bit NBMIO-16 analogue-digital board and a Macintosh Quadra 700 computer (Apple Computer, Inc., Cupertino, CA, USA) running LabVIEW® software (National Instrum-

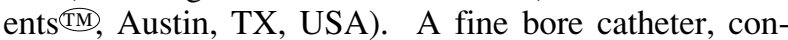
necting the mouthpiece of the mouth pressure meter to the Validyne pressure transducer, enabled simultaneous measurement by mouth pressure meter and laboratory standard. LabVIEW was programmed to analyse the pressure signal in the same way as described for the portable mouth pressure meter. The laboratory standard was calibrated before each subject against a water manometer.

We assessed 13 normal subjects (mean age 33 yrs, range $24-44$ yrs; mean vital capacity mean $4.2 l$, range 2.3-6.3l), and 11 patients with respiratory disease (mean age 51 yrs, range 19-77 yrs; mean vital capacity $2.4 l$, range $0.4-5.0 l$ ). Most of the subjects were unfamiliar with the techniques involved. For each test, maximal manoeuvres were first demonstrated by the examiner. The subject was instructed to insert the flanged mouthpiece [8], hold it with the teeth and take one or two breaths through the nose, whilst becoming accustomed to the mouthpiece. A noseclip was fitted, and for PImax the subject was asked to breathe out gently to residual volume. The subject was then encouraged to make a maximal inspiratory effort for 2-3 s. The manoeuvre was repeated five times. For Pemax the subject was instructed to breathe to total lung capacity (TLC), and then encouraged to make a maximal expiratory effort for 2-3 s. Pemax was also repeated five times. The subjects were given strong verbal encouragement but no visual feedback.

The agreement between the two methods was analysed according to the recommendations of BLAND and ALTMAN [10].

\section{Results}

The 24 subjects produced a total of 120 inspiratory and 120 expiratory efforts. Four efforts, all in patients, were rejected by the mouth pressure meter because pressures generated were below $2 \mathrm{kPa}$. One effort was sustained for less than $1.5 \mathrm{~s}$, with the consequent loss of one Pmax value. These five efforts resulted in five values of zero for Pmax and four values of zero for peak pressure, for the mouth pressure meter. For the remaining 235 efforts, there was excellent agreement comparing the mouth pressure meter and laboratory standard, both for peak pressure and Pmax values (figs 3 and 4). Comparison of inspiratory peak values showed a mean \pm SD difference of $0.12 \pm 0.20 \mathrm{kPa}$ and of expiratory peak values $-0.14 \pm 0.18 \mathrm{kPa}$. The difference for Pmax was $0.19 \pm 0.12 \mathrm{kPa}$ for inspiratory efforts and $-0.04 \pm 0.12 \mathrm{kPa}$ for expiratory efforts. These differences were very small (fig. 5), and none were statistically significant (paired ttest). 

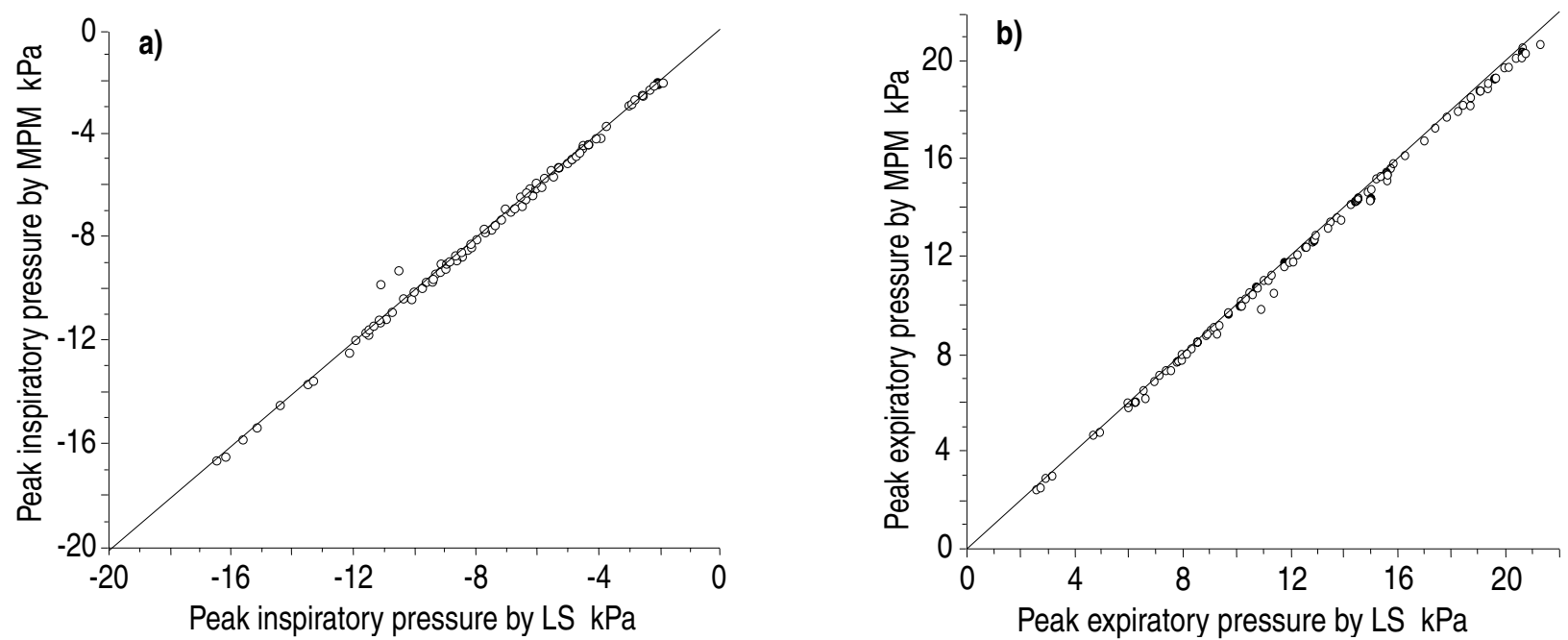

Fig. 3. - Comparison of peak pressure by the mouth pressure meter (MPM) and laboratory standard (LS) with line of identity. a) peak inspiratory pressure; b) peak expiratory pressure.
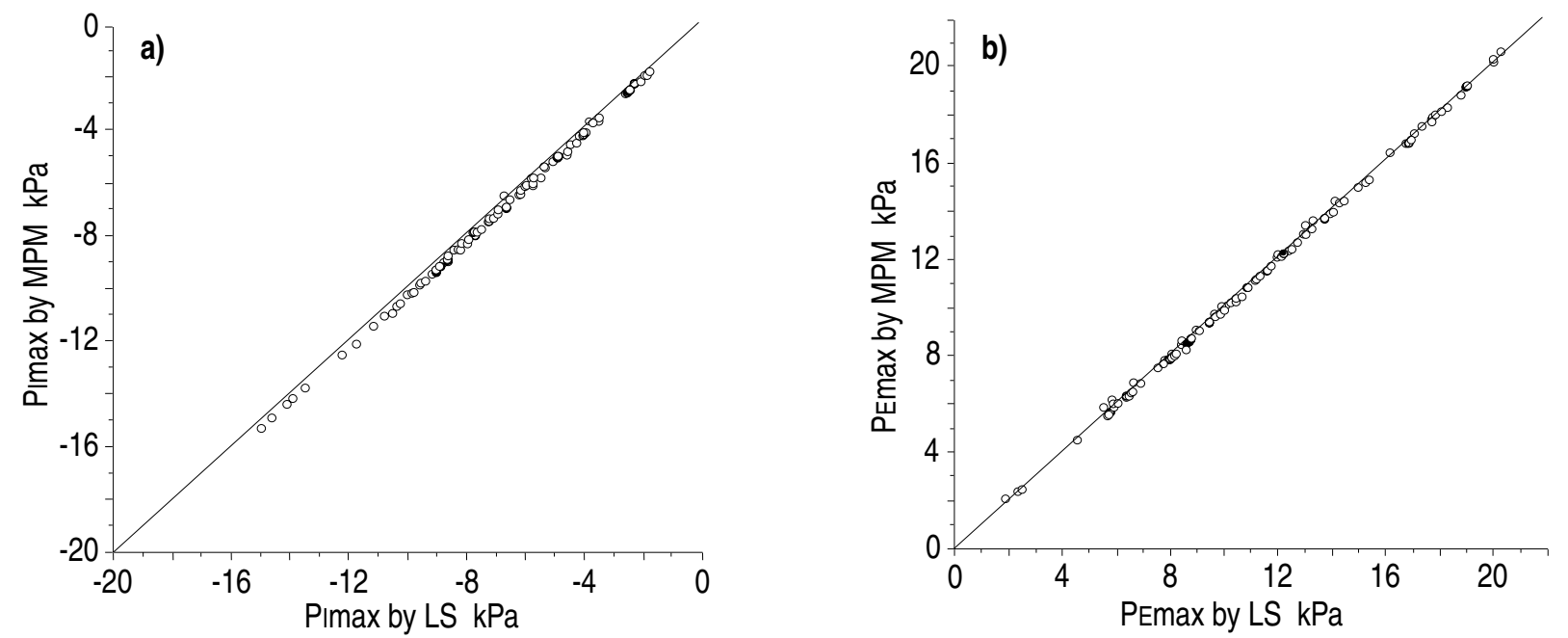

Fig. 4. - Comparison of the maximum pressure by the mouth pressure meter (MPM) and laboratory standard (LS) with line of identity. a) maximum inspiratory pressure (PImax); b) maximum expiratory pressure (Pemax).

a)

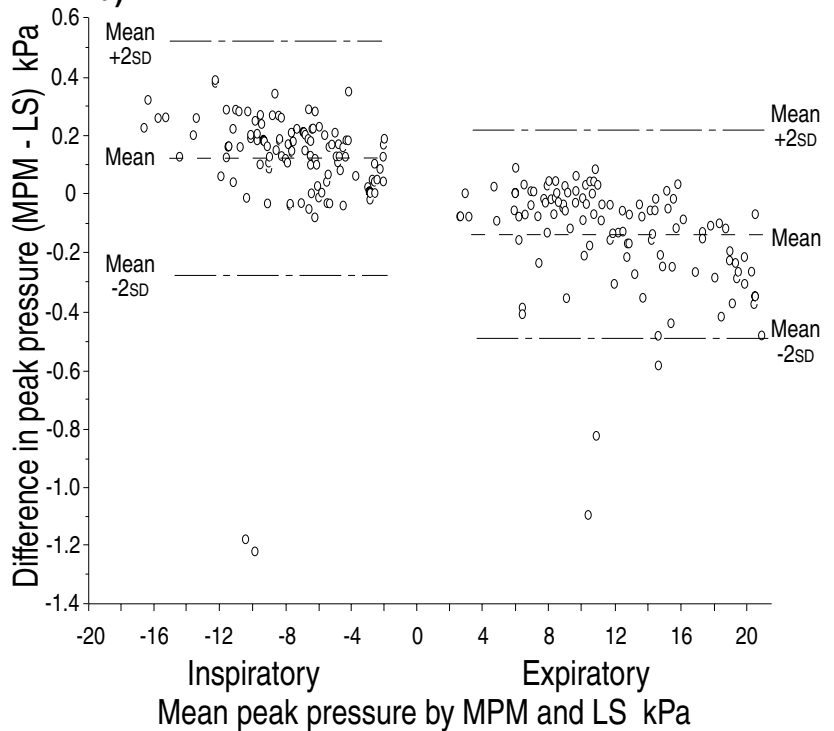

b)

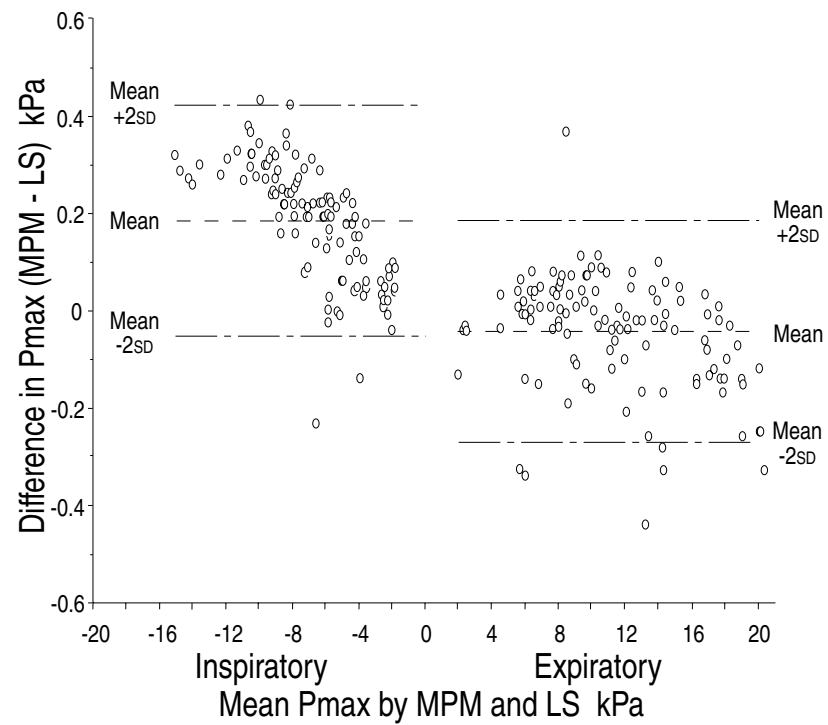

Fig. 5. - Altman and Bland plot [10] of the difference between the two methods of pressure measurement over the mean values. a) peak pressure; b) maximum pressure averaged over one second (Pmax). 


\section{Discussion}

Comparison of the mouth pressure meter and the laboratory standard equipment yielded almost identical results, confirming the accuracy and reproducibility of the portable meter. Throughout the study, calibration of our laboratory standard was checked regularly. A commendable design feature of the mouth pressure meter is the facility to check and adjust static calibration against a known reference pressure, and this was checked. We did not readjust the calibration of the meter, as we wished to assess its performance in circumstances similar to the out-patient clinic, where it would be unlikely that frequent calibration checks would be undertaken. The duration of our study was 8 weeks, and during this period there was no drift. The fast frequency response of the Validyne $(30-40 \mathrm{~Hz})$ LabVIEW sampling at $100 \mathrm{~Hz}$, and the agreement between the results from the two systems, confirms that the frequency response of the portable meter and its sampling rate of $16 \mathrm{~Hz}$ are adequate for accurate measurement of maximal pressures.

The mouth pressure meter measures the average maximum (or minimum) mouth pressure achieved over a one second period, and this analysis was reproduced by LabVIEW. Traditionally, Pmax has been measured visually from pressure tracings. Since it is hard to estimate average maximum pressure visually, Pmax has usually been identified as that pressure which is sustained throughout the one second period. This sustained pressure is, of course, slightly lower than that averaged over the one second period. We compared the "average" Pmax with "sustained" Pmax and found a mean \pm SD difference of $0.88 \pm 0.46 \mathrm{kPa}$ for Pimax and $0.70 \pm 0.70 \mathrm{kPa}$ for PEmax, with smaller differences at lower pressures. Average pressure sustained over one second is, in theory, a better reflection of the maximal strength of the muscles. The ability of the mouth pressure meter to calculate in this way is probably an advantage, and is likely to increase the discriminatory power of the technique in the clinical setting.

In conclusion, the mouth pressure meter reliably and accurately measured peak pressure and Pmax both for inspiratory and expiratory efforts. The meter is portable and robust. It should allow scientific measurement of respiratory muscle strength in the clinic, at the bedside, in field studies, and in hospitals where the equipment and expertise for full muscle evaluation is not available. By having these measurements easily accessible, we believe the meter may play an important role in promoting respiratory muscle evaluation as a research and clinical technique.

\section{References}

1. Laroche CM, Moxham J, Green M. Respiratory muscle weakness and fatigue. $Q J$ Med 1989; 71: 373-397.

2. Ringqvist $T$. The ventilatory capacity in healthy subjects: an analysis of causal factors with special reference to the respiratory forces. Scand J Clin Invest 1966; 18 (Suppl. 88): 8-170.

3. Black LF, Hyatt RE. Maximal respiratory pressures: normal values and relationships to age and sex. Am Rev Respir Dis 1969; 99: 696-702.

4. Green M. Respiratory muscle testing. Bull Eur Physiopathol Respir 1984; 20: 433-436.

5. Moxham J. Tests of Respiratory Muscle Function. In: Tobin MJ, ed. Problems in Respiratory Care, Philadelphia, Lippincott, September 1990; 3: pp. 312-328.

6. Wilson SH, Cooke NT, Edwards RHT, Spiro SG. Predicted normal values for maximal respiratory pressures in Caucasian adults and children. Thorax 1984; 39: 535-538.

7. Vincken W, Ghezzo H, Cosio MG. Maximal respiratory pressures in adults: normal values and their relationship to determinants of respiratory function. Bull Eur Physiopathol Respir 1987; 23: 435-439.

8. Koulouris N, Mulvey DA, Laroche CM, Green M, Moxham J. Comparison of two different mouthpieces the measurement of PImax and PEmax in normal and weak subjects. Eur Respir J 1988; 1: 863-867.

9. Bruschi C, Cervezi I, Zoia M, et al. Reference values of maximal respiratory mouth pressures: a populationbased study. Am Rev Respir Dis 1992; 146: 790-793.

10. Bland JM, Altman DG. Statistical methods for assessing agreement between two methods of clinical measurement. Lancet 1986; i: 307-310. 